\title{
Alteration of the shoot radial pattern in Arabidopsis thaliana by a gain-of-function allele of the class III HD-Zip gene INCURVATA4
}

\author{
ISABEL OCHANDO ${ }^{1, \#, ~ S A N T I A G O ~ G O N Z A ́ L E Z-R E I G \#, ~ J U A N-J O S E ́ ~ R I P O L L ~}{ }^{2}$, ANTONIO VERA \\ and ANTONIO MARTÍNEZ-LABORDA*
}

Area de Genética, Universidad Miguel Hernández, Campus de Sant Joan d'Alacant, E-03550 Alicante, Spain

\begin{abstract}
Class III HD-Zip (HD-Zip III) family genes play key roles in a number of fundamental developmental programs in Arabidopsis thaliana, such as embryo patterning, meristem initiation and homeostasis, lateral organ polarity and vascular development. Semidominant gain-offunction alleles of the HD-Zip III genes PHABULOSA (PHB), PHAVOLUTA (PHV) and REVOLUTA (REV) disrupt the negative regulation of these genes by a mechanism of microRNA interference. We provide evidence that the gain-of-function icu4-1 allele of INCURVATA4, a gene encoding the HD-Zip III transcription factor ATHB15/CORONA (CNA), stimulates the production of vascular tissues, supporting a role for ICU4 in promoting vascular development. Occasionally, homozygous mutants for this allele show a reduced number of thick shoot vascular bundles, although normal collateral polarity remains unchanged. Genetic analysis of icu4-1 and phb-1D, a gain-offunction allele of the related $P H B$ gene, revealed antagonism in lateral organ polarity between both mutations and a synergistic interaction in shoots, with transformation of the polarized collateral bundles into a radialized amphivasal pattern. These results indicate that the precise regulation of HD-Zip III genes confers positional information which is required to establish the number and pattern of vascular bundles in the stem. In addition, we present results that suggest an interaction between ICU4 function and auxin signaling.
\end{abstract}

KEY WORDS: Arabidopsis, class III HD-Zip gene, shoot radial pattern, vascular development

\section{Introduction}

The vasculature, a distinguishing feature of vascular plants, consists of an intricate network of conducting tissues that interconnect the different parts of the plant body, allowing the transport of water and solutes such as mineral nutrients, photoassimilates and signal molecules. Vascular plants already existed in the Silurian period, 438 to 408 million years ago, the evolution and diversification of their vascular systems being among the key events for efficient land colonization by plants. The vasculature is composed of the vascular meristematic tissues procambium and vascular cambium, responsible for the development of primary and secondary vascular tissues, respectively, and two differentiated tissues, xylem and phloem, each consisting of several specific cell types. Given the basic functions carried out by the vascular system, its accurate differentiation and patterning is a crucial process in plant development (Ye, 2002; Ye et al., 2002).

Plant vascular patterns are species-specific traits, which suggests that they are subject to genetic control and may represent good models for the study of genetic and molecular mechanisms involved in pattern formation. Several studies have pointed to the importance of auxin for the differentiation of vascular tissues (Jacobs, 1952; Young, 1953; Aloni, 1987), as well as the implication of other plant hormones like cytokinin (Fukuda, 1997) and brassinosteroids (Yamamoto et al., 1997; Caño-Delgado et al., 2004). In fact, auxin plays a determinant role not only in vascular

Abbreviations used in this paper: CNA, CORONA; HD-Zip III, class III HD-Zip gene; ICU, INCURVATA; NAA, naphthylacetic acid; PHB, PHABULOSA; PHV, PHAVOLUTA; REV, REVOLUTA.

*Address correspondence to: Antonio Martínez-Laborda. División de Genética, Universidad Miguel Hernández, Campus de San Juan, E-03550 Alicante, Spain. Tel: +34-965-919-476. Fax: +34-96-591-9568. e-mail: laborda@umh.es

Notes: \# These authors have contributed equally to this work. 1 Present address: Unidad de Reproducción Asistida. Clínica Vistahermosa. Avda. de Denia 103, 03015-Alicante, Spain. 2 Present address:Division of Biological Sciences, University of California San Diego, La Jolla, CA 92093, USA. 
cell differentiation, but also in producing the continuity of vascular strands that finally become organized in a defined pattern (Sachs, 1981; 1991; Berleth et al., 2000). Auxin is synthesized in the apical tissues and moves basipetally in the shoot, according to a mechanism that involves its polar transport from cell to cell in a process mediated by the asymmetric localization of influx and efflux auxin carriers (Muday and DeLong, 2001; Muday and Murphy, 2002).

Five class III HD-Zip (HD-Zip III) gene family members have been identified in the Arabidopsisgenome: PHABULOSA (PHB), PHAVOLUTA (PHV), REVOLUTAIINTERFASCICULAR
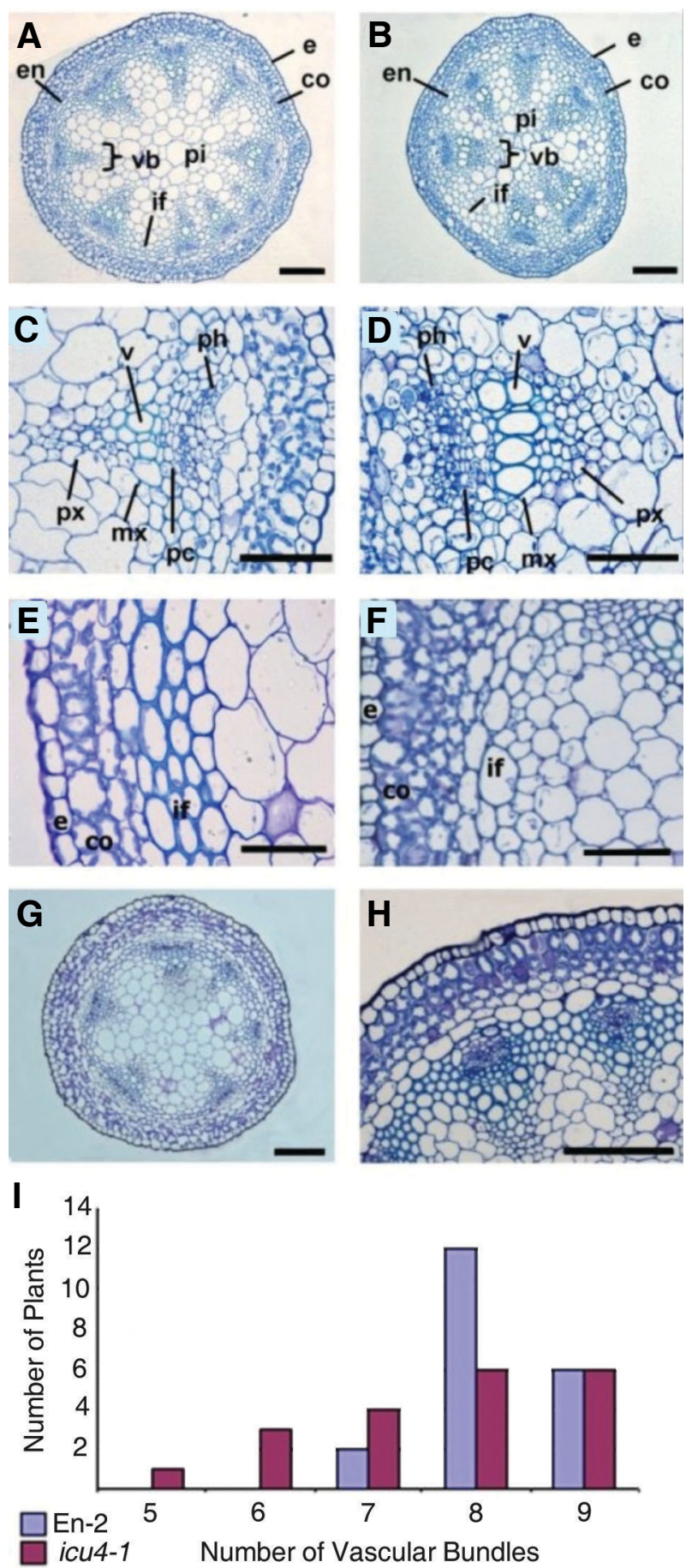

FIBERLESS1(REVIFL 1), ATHB8, and ATHB15/CORONA(CNA)/ INCURVATA4 (ICU4). These genes are involved in several key developmental processes, including vascular development. The expression of $A T H B 8$ is restricted to procambial cells (Baima et al., 1995), and its overexpression in transgenic plants promotes vascular cell differentiation, increasing the formation of xylem tissue (Baima et al., 2001). Transcripts of the adaxial identity genes $P H B, P H V$ and $R E V$ accumulate in the adaxial side of lateral organs and are absent from the abaxial side (McConnell et al., 2001; Otsuga et al., 2001), the adaxial region being the closest to the meristem and the abaxial the farthest. Semidominant gainof-function alleles of $P H B, P H V$ and $R E V$ disrupt the regulation of these genes by microRNA (miRNA), causing the ectopic accumulation of their mRNA in the abaxial side of leaves, which produces abaxial-to-adaxial transformations (McConnell et al., 2001; Emery et al., 2003; Zhong and Ye, 2004). These alleles have also been reported to affect the pattern within leaf veins, as they cause the transformation of the normal collateral arrangement, consisting of adaxial xylem and abaxial phloem, into a radialized amphivasal pattern, with xylem surrounding phloem (McConnell and Barton, 1998; Zhong and Ye, 2004). In addition, the semidominant alleles of $R E V$ also produce this same transformation in the vascular bundles that extend longitudinally within the inflorescence stem (Emery et al., 2003; Zhong and Ye, 2004). Accordingly, vascular bundles of triple mutants for loss-of-function alleles in the abaxial KANADI family genes KAN1, KAN2 and KAN3 also display an amphivasal pattern (Emery et al., 2003).

A genetic analysis of icu4-1 and icu4-2, two semidominant gain-of-function alleles of the HD-Zip III gene $\mathrm{CNA} / \mathrm{ICU} 4$, which codes for the ATHB15 transcription factor (Prigge et al., 2005), has shown that both carry the same point mutation perturbing the binding site of miR165/166, giving rise to increased levels of the mutant mRNA in every organ, and that the gene product possesses adaxial activity (Ochando et al., 2006). In this report, we show that homozygosis for the icu4-1allele results in an increase of vascular tissues in inflorescence stems, which supports the idea that /CU4promotes vascular development. Moreover, plants carrying gain-of-function mutations in both /CU4and PHBdisplay shoots with amphivasal bundles, indicating a crucial role for the precise regulation of HD-Zip III gene expression in the establish-

Fig. 1. Effects of the icu4-1 mutation on vascular development in inflorescence stems. Sections were taken from the middle portions of inflorescence stems of 60 day-old plants. (A) Transverse section of a wild-type (En-2) inflorescence stem showing nine vascular bundles. (B) Transverse section of an icu4-1 inflorescence stem showing six vascular bundles. (C) A close-up view of an En-2 vascular bundle. (D) A close-up view of an icu4-1 vascular bundle. (E) A close-up view of En-2 interfascicular fiber cells. (F) A close-up view of icu4-1 interfascicular fiber cells showing thin secondary walls. (G) Transverse section of the inflorescence stem from a transgenic plant harboring the 35S-ICU4-G189D transgene, showing a phenotype reminiscent to that of icu4-1. $(\mathbf{H})$ Transverse section of the inflorescence stem from a transgenic plant harboring the 35S-ICU4-G189D transgene, showing a partial transformation to amphivasal polarity in the vascular bundles. (I) Number of vascular bundles were counted from 20 inflorescence stems from each genotype, wild-type (En-2) and icu4-1. co, cortex; e, epidermis; en, endodermis; if, interfascicular fibers; $m x$, metaxylem; ph, phloem; pi, pith; pc, procambium; px, protoxylem; $v$, vessel element; vb, vascular bundle. Scale bars indicate $100 \mu \mathrm{m}$ in panels (A, B, G and H), and $50 \mu \mathrm{m}$ in panels (C-F). 
ment of the radial pattern of inflorescence stems. In addition, altering the auxin signaling pathway in the icu4-1 mutant also modifies the shoot radial pattern, which suggests a collaboration between ICU4 (and also other HD-Zip III genes) and auxin in its establishment. Our results represent novel findings on the complexity of the interactions between mutant alleles of HD-Zip III genes.

\section{Results}

\section{Inflorescence stem vascular pattern of the icu4-1 mutant and transgenic plants overexpressing icu4-1 cDNA}

Transverse sections in nonelongating internodes of the En-2 wild-type inflorescence stems (Fig. 1A) show a radial pattern similar to that described in other Arabidopsisaccessions (Altamura et al.; 2001; Ye et al., 2002). From the outside to the inside, the inflorescence stem shows an epidermal cell layer, three layers of cortex and one layer of endodermis. Below the endodermis, eight or nine vascular bundles are arranged in a eustele, as they form a ring-like pattern around a pith of large parenchyma cells. Located between the vascular bundles, the interfascicular regions display three or four layers of thick interfascicular fiber cells adjacent to the endodermis (Fig. $1 \mathrm{~A}$ and $\mathrm{E}$ ). The vascular bundles have a polarized collateral pattern, with phloem close to the peripheral region of the inflorescence stem, xylem near the central region and the procambium positioned in-between (Fig. $1 \mathrm{C)}$.

The icu4-1allele, a semidominant gain-of-function allele of the HD-Zip III family member ATHB15/CNA//CU4, gives rise to the accumulation of large amounts of the mutant mRNA in the inflorescence stem (Ochando et al., 2006). The homozygous icu4-1 mutant shows an alteration in the shoot vascular pattern, consisting of a reduction in the number of vascular bundles compared with the wild type, as seen in inflorescence stems with only five or six bundles (Fig. 1B). This phenotype is shown with incomplete penetrance (Fig. 1I). Vascular bundles are generally larger in icu4-1, and many of them adopt a rectangular or trapezoidal shape instead of the common isosceles triangle shape observed in its wild-type ancestor En-2 (Fig. 1B and D). This is probably due to an increase of vascular tissues in the mutant bundles, which show extra layers of procambium, an overproliferated phloem, and a more modest increase of xylem, although the metaxylem contains very large vessels (Fig. 1D; Table 1). Transverse sections of En-2 and icu4-1 shoots display the same area $\left(A_{S} ;\right.$ Table 1$)$. Therefore, given that the average total area of vascular tissues per inflorescence stem is greater in the icu4-1 mutant ( $\mathrm{A}_{\mathrm{VB}}$; Table 1), the latter displays a conspicuous increase in the amount of vascular tissue related to the shoot area, as compared with $\mathrm{En}-2\left(\mathrm{~A}_{\mathrm{VB}} / \mathrm{A}_{\mathrm{S}}\right.$; Table 1), indicating that the formation of large vascular bundles in icu4-1 is independent of shoot thickness. Considering the gain-of-function nature of the icu4-1 allele, this fact suggests that ICU4 promotes vascular tissue formation in the bundles. Another trait occasionally observed in the mutant is a poor lignification of interfascicular fiber cells (Fig. 1E and F).

Several classes of 35S-/CU4-G189D transgenic plants, which overexpress the mutant icu4-1 cDNA, were previously isolated (Ochando et al., 2006). One of them included plants with a leaf phenotype similar to that of the icu4-1 mutant. These transgenic
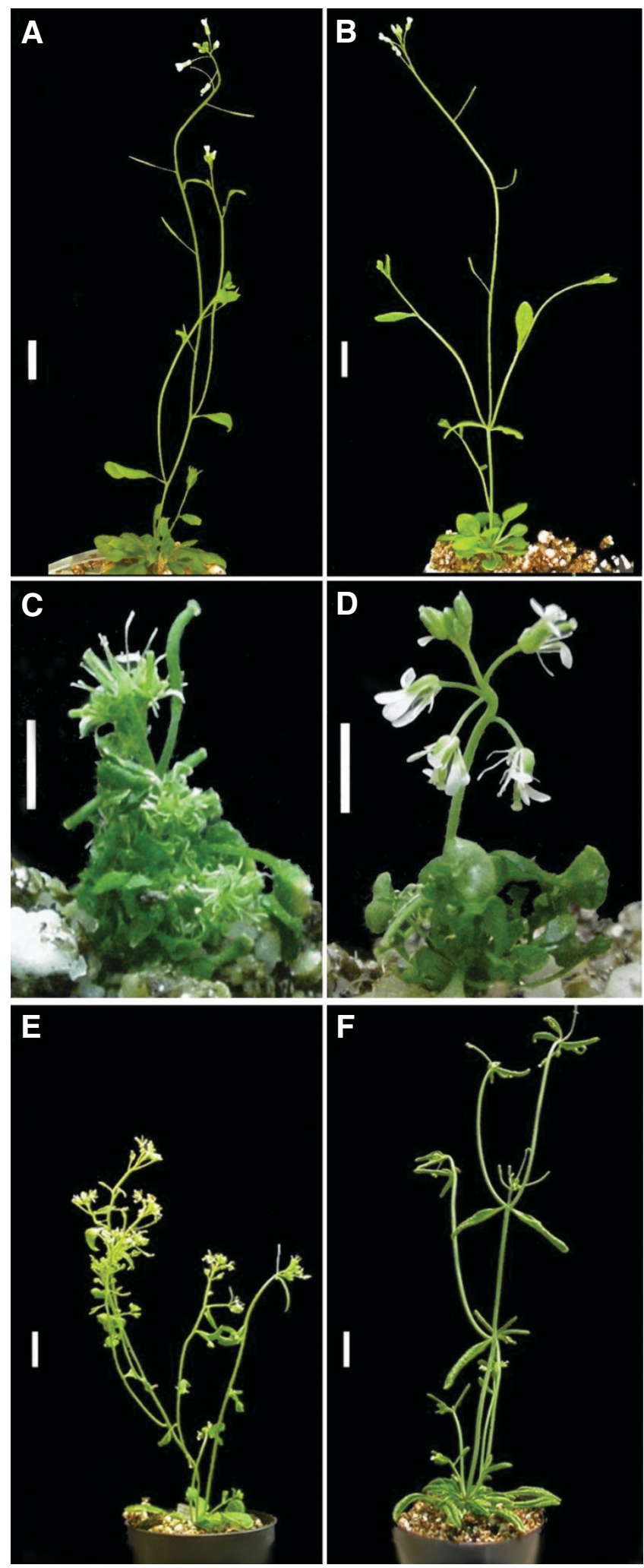

Fig. 2. Morphological phenotypic traits of double mutants involving the icu4-1 allele. 8-week-old (A) En-2 wild-type accession, (B) icu4-1/ icu4-1, (C) phb-1D/PHB, (D) phb-1D/PHB;icu4-1/CU, (E) fil-3/fil-3, and (F) fil-3Ail-3,icu4-1/1cu4-1 plants. Scale bars indicate $5 \mathrm{~mm}$ in (C,D) and $1 \mathrm{~cm}$ in $(A, B, E$ and $F)$. 
plants also showed the same phenotype of reduction in the number of vascular bundles than icu4-1 (Fig. 1G). Other 35SICU4-G189D transgenic plants of stronger phenotype showed radialized and trumpet-shaped leaves. The number of vascular bundles was similar to that of the En-2 accession in these latter plants, but the arrangement of cell types within the bundles was altered. The phloem adopted a rounded shape and, in most vascular bundles, was surrounded by xylem, so that there was a partial transformation of the wild-type collateral bundles to amphivasal types (Fig. 1H). A third class of 35S-/CU4-G189D transgenic plants showed completely radialized leaves and never flowered (Ochando et al., 2006).

\section{icu4-1 interacts with mutations in adaxial and abaxial identity genes}

Plants of the homozygous icu4-1mutant show altered phyllotaxis and frequently exhibit two cauline leaves with their associated paraclades emerging from the same node (Fig. 2A and B), as previously described (Ochando et al., 2006). A semidominant allele of the $P H B$ gene, phb-1D, transforms the abaxial tissues of lateral organs into adaxial tissues (McConnell and Barton, 1998). The phb-1D/ PHB plants are bushy due to the formation of extra axillary buds next to the ectopic adaxial leaf tissues, and exhibit a variable degree of radial symmetry in all lateral organs (Fig. $2 C$ ). Given the high similarity of $/ C U 4$ and $P H B$, and the molecular and
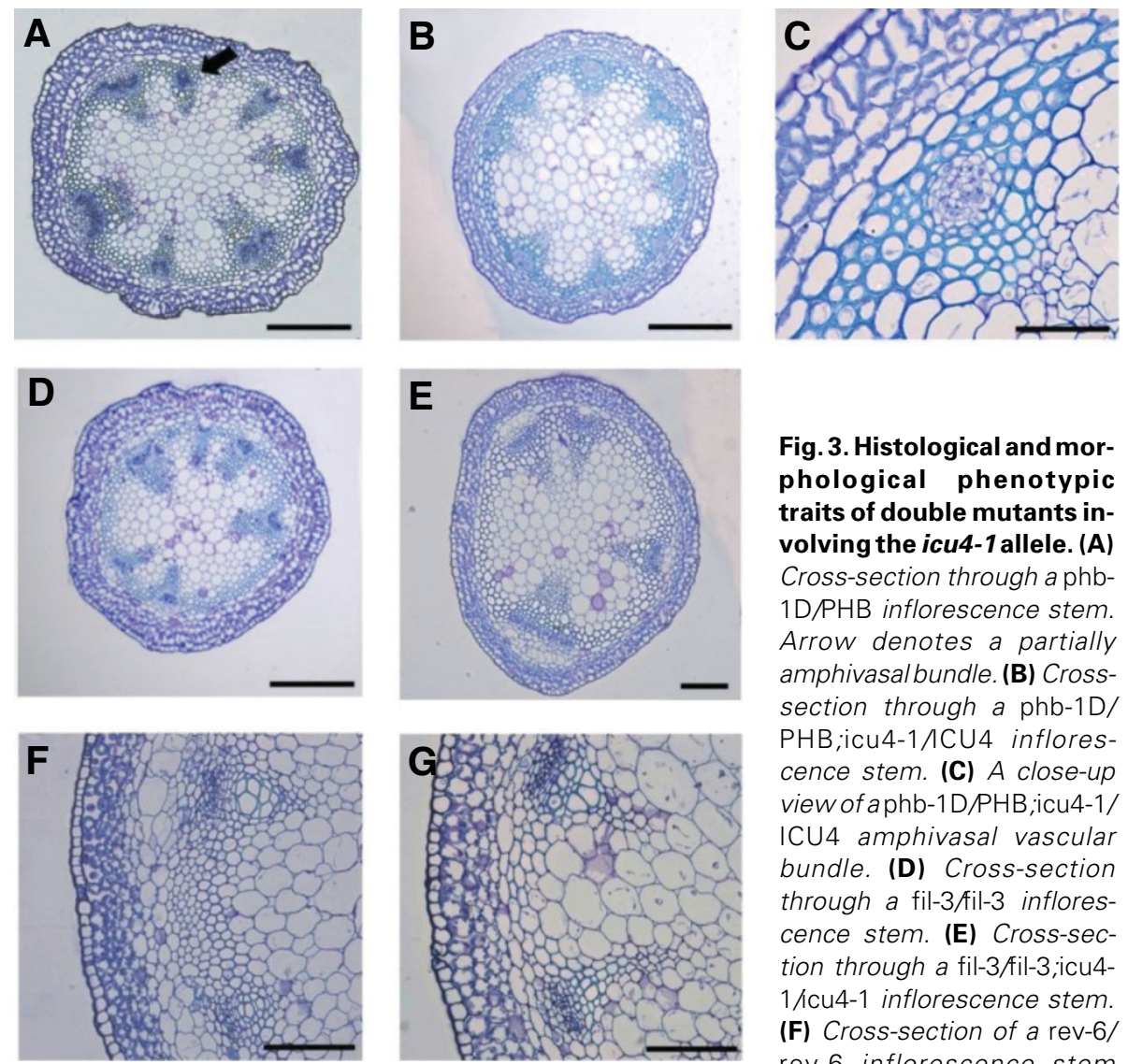

Fig. 3. Histological and morphological phenotypic traits of double mutants involving the icu4-1 allele. (A) Cross-section through a phb1D/PHB inflorescence stem. Arrow denotes a partially amphivasal bundle. (B) Crosssection through a phb-1D/ PHB;icu4-1/ACU4 inflorescence stem. (C) A close-up view of a phb-1D/PHB,icu4-1/ ICU4 amphivasal vascular bundle. (D) Cross-section through a fil-3Ail-3 inflorescence stem. (E) Cross-section through a fil-3/fil-3;icu41/1cu4-1 inflorescence stem. (F) Cross-section of a rev-6/ rev-6 inflorescence stem showing the absence of normal interfascicular fiber cells. (G) Cross-section of a rev-6/rev-6;icu41/1cu4-1 inflorescence stem showing the presence of thin interfascicular fiber cells. Scale bars indicate $50 \mu \mathrm{m}$ in panel (C), $100 \mu \mathrm{m}$ in panels (E-G) and $250 \mu \mathrm{m}$ in panels (A, B and D).
TABLE 1

\section{HISTOLOGICAL ANALYSIS OF INFLORESCENCE STEMS}

\begin{tabular}{|c|c|c|c|c|c|c|}
\hline & $\begin{array}{l}\text { Phloem Area } \\
\left(\mu \mathrm{m}^{2}\right)\end{array}$ & $\begin{array}{l}\text { Procambium } \\
\text { Area }^{\mathrm{a}} \\
\left(\mu \mathrm{m}^{2}\right)\end{array}$ & $\begin{array}{l}\text { Xylem } \\
\text { Area }^{a} \\
\left(\mu \mathrm{m}^{2}\right)\end{array}$ & $\begin{array}{l}\text { Stem } \\
\text { Area }\left(\mathbf{A}_{\mathbf{S}}\right)^{\mathrm{b}} \\
\left(\mu \mathbf{m}^{2}\right)\end{array}$ & $\begin{array}{c}\text { Vascular Bundle } \\
\text { Area }\left(\mathbf{A}_{\mathrm{VB}}^{\mathrm{b}}\right)^{\mathrm{b}} \\
\left(\mu \mathrm{m}^{2}\right)\end{array}$ & $A_{V B} / A_{S}$ \\
\hline $\begin{array}{c}\text { wild-type } \\
\text { (En-2) }\end{array}$ & $\begin{array}{r}1035.53 \\
\pm 165.96\end{array}$ & $\begin{array}{l}456.09 \\
\pm 93.46\end{array}$ & $\begin{array}{c}4356.5 \\
\pm 978.71\end{array}$ & $\begin{array}{c}454366.9 \\
\pm 162523.7\end{array}$ & $\begin{array}{c}68444.99 \\
\pm 22536.15\end{array}$ & $\begin{array}{c}0.152 \\
\pm 0.018\end{array}$ \\
\hline icu4-1 & $\begin{array}{l}1597.96 \\
\pm 293.64\end{array}$ & $\begin{array}{r}1123.05 \\
\pm 277.05\end{array}$ & $\begin{array}{c}5920.36 \\
\pm 1315.65\end{array}$ & $\begin{array}{c}451585.9 \\
\pm 131194.8\end{array}$ & $\begin{array}{c}84316.94 \\
\pm 18708.39\end{array}$ & $\begin{array}{c}0.190 \\
\pm 0.018\end{array}$ \\
\hline
\end{tabular}

a Each value represents the average of ten $1 C U 4$ and ten icu4-1 vascular bundles from three

phenotypic similarities of their semidominant alleles, we expected a mutual enhancement of the icu4-1 and phb-1D mutations. However, the phb-1DPHB;icu4-1/ICU4 diheterozygotes do not show the expected strong phenotype. Instead, these plants display a weaker phenotype (Fig. 2D), being less bushy and with between these two alleles also affects vascular patterning of shoots, we have compared cross-sections of heterozygous phb$1 D / P H B$ and double heterozygous icu4-1//CU4; phb-1D/PHB inflorescence stems. The number and position in the eustele of vascular bundles are both unaffected in $p h b-1 D$ heterozygotes, although several bundles have an increased size and, more seldom, one or two of them may adopt a partial amphivasal pattern (Fig. $3 A)$. Inflorescence stems of the double heterozygote also show a normal number and position of vascular bundles, but surprisingly these exhibit a conspicuous amphivasal pattern (Fig. 3B and C). Thus, unlike the adaxialized phenotype observed in lateral organs, in which icu4-1 antagonizes the effect of phb-1D, this amphivasal phenotype shows that, in the vascular bundles, there is a synergistic interaction between both alleles. These results indicate that the HD-Zip III genes ICU4and PHBfunctionally interact in different ways depending on the organ, antagonistically in leaves and synergistically in vascular bundles.

Strong loss-of-function alleles of REV cause a reduction in the initiation of lateral shoot and flower meristems (Talbert et al., 1995; Otsuga et al., 2001). In addition, these alleles produce a mutant phenotype of the interfascicular fiber cells that normally develop adjacent to the endodermis, whose differentiation is blocked in revhomozygotes (Fig. 3F) (Zhong et al., 1997; Zhong and Ye, 1999). This phenotype, which is suppressed by the double homozygosis of null alleles in ICU4 and ATHB8 (Prigge et al., 2005), is also rescued in a double mutant carrying the 
icu4-1 allele and rev-6, a null allele of REV. Thus, icu4-1 rev-6 plants displayed interfascicular fiber cells in their normal position, although they showed the reduced thickness previously observed in icu4-1 (Fig. 3G). A similar result was obtained in a double mutant with the rev-1 allele (Talbert et al., 1995), which also differentiated icu4-1-like interfascicular fiber cells next to the endodermis (data not shown). These results suggest that overexpression by the icu4-1 allele can compensate for the loss of REV function, at least in the formation of interfascicular fiber cells.

The F/L gene, a YABBY family member, regulates the development of flower and inflorescence meristems, and the abaxial identity of lateral organs (Chen et al., 1999; Sawa et al., 1999). The hypomorphic fil-3 allele produces weak defects in flower formation and partial adaxialization of flower organs (Fig. 2E). This phenotype increases with the contribution of the icu4-1 allele. The double mutant shows low number of flowers, long pedicels and internodes, flowers subtended by cauline leaves, and stronger adaxialization of flower organs (Fig. 2F). Crosssections of fil-3inflorescence stems usually reveals six or seven vascular bundles (Fig. 3D). Transverse sections of icu4-1 fil-3 inflorescence stems also show a stronger phenotype. There are only three or four vascular bundles, numbers never observed in either of the two single mutants (Fig. 3E). The icu4-1 fil-3 double mutant was easily distinguished from $F_{2}$ wild-type and single mutant plants, indicating that the increase in the mutant phenotype is not due to mixing accessions and/or loss of the $\mathrm{Er}^{-}$ phenotype of fil-3 plants. The low number of vascular bundles seen in icu4-1 fil-3stems shows again that misregulation of ICU4 by the icu4-1 allele reduces the number of bundles in the eustele, and demonstrates the participation of abaxial identity genes, like $F / L$, in the proper establishment of this pattern.

\section{Effects of auxin on eustele organization}

Many of the mutations in HD-Zip III genes affect processes regulated by auxin, suggesting a connection between the function of these genes and auxin signaling. One of the processes in which both pathways are involved is vascular development. Therefore, to verify a possible interaction between ICU4 and auxin signaling in the radial patterning of shoots, we investigated the effect of treatments with naphthylacetic acid (NAA), a synthetic auxin, on the phenotype of En-2 and icu4-1 shoots. To verify the efficacy of the treatment, we monitored the induction of the auxin-response genes $I A A 1$ and $I A A 19$ (Fig. 4). At 8 hours of NAA treatment, we observed induction of both genes in the En-2 accession. However, when the treatment was extended to 56 hours, there were no difference between NAA- and mock-treated plants, as seen by

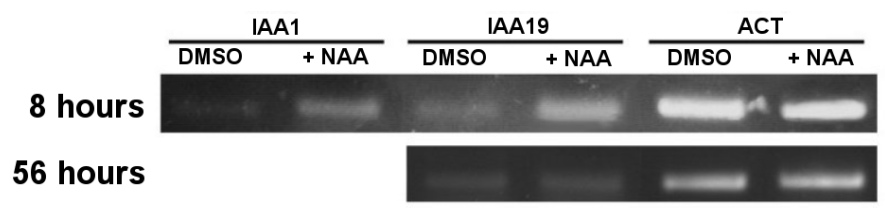

Fig. 4. Semiquantitative RT-PCR analysis of IAA1 and IAA19. Induction of the expression of IAA1 and IAA19 in leaves after 8 hours of naphthylacetic acid (NAA) treatment as compared to mock-treated (DMSOtreated) plants. Similar levels of IAA19 expression were detected in NAAtreated and control (DMSO-treated) plants after 56 hours of treatment. ACTIN2 (ACT2) expression was analyzed as an internal control.
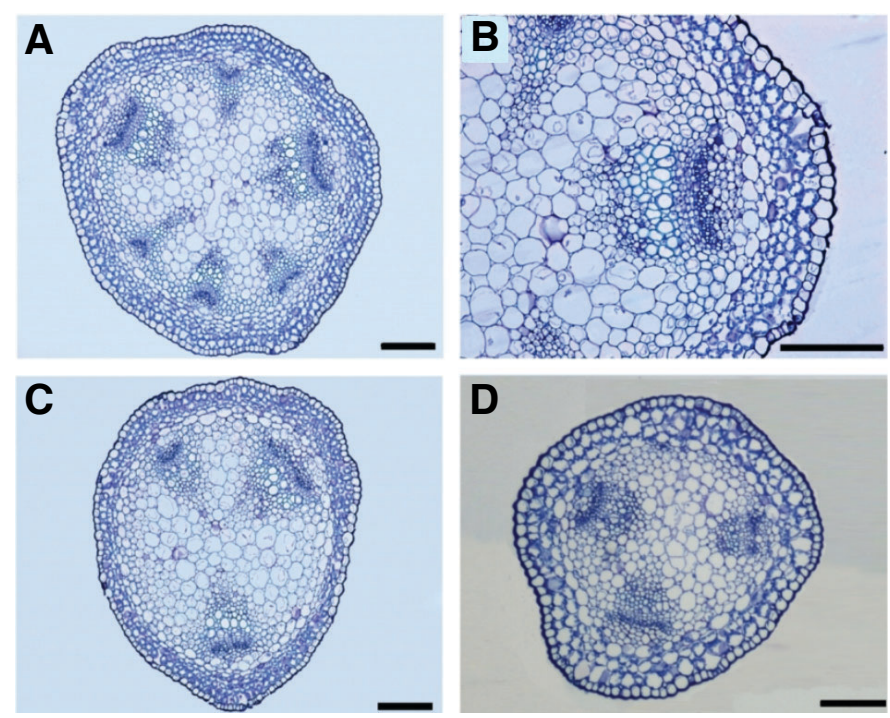

Fig. 5. Effects of naphthylacetic acid (NAA) treatments. (A) Transverse section of an En-2 inflorescence stem treated with $1 \mu M N A A$, showing a reduced number of large collateral bundles. (B) A close-up view of a vascular bundle from (A). (C) Transverse section of an icu4-1 inflorescence stem treated with $1 \mu \mathrm{MNAA}$, showing an enhancement of the mutant phenotype. (D) Transverse section of a phb-1D inflorescence stem treated with $1 \mu M N A$, showing only three vascular bundles. Scale bars indicate $100 \mu \mathrm{m}$.

the similar levels of IAA19mRNA, suggesting that the effect of NAA on the shoot radial pattern occurs early at bolting, coinciding with the beginning of the treatment.

Control plants with mock treatment showed the same phenotypes as previously described for En-2 and icu4-1 plants. En-2 plants treated with NAA phenocopied the inflorescence stem phenotype that characterizes the icu4-1 mutant. Five out of seven plants showed stems with only six bundles (Fig. 5A), while the remaining two plants showed stems with seven bundles. In these stems, some vascular bundles had the same aspect as those of icu4-1, exhibiting a rectangular or trapezoidal shape, and overproliferated procambium, phloem and xylem, as well as large metaxylem vessels (Fig. 5B). Treatment of icu4-1plants with NAA enhanced the mutant phenotype. Most shoots had three (three out of seven shoots) or four (two out of seven shoots) large vascular bundles (Fig. $5 \mathrm{C}$ ), numbers never seen in untreated icu4-1 plants. The remaining two plants showed five and seven vascular bundles. Treatment of heterozygous phb-1Dplants with NAA resulted in a similar phenotype of reduction in the number of vascular bundles (Fig. 5D). As a whole, these results indicate that the shoot phenotypes produced by the wild-type, icu4-1 and phb$1 D$ alleles are influenced by auxin, and suggest that HD-Zip III genes and the auxin signaling pathway might be collaborating in the establishment of the radial pattern of shoots.

As auxin has an essential role in lateral root formation and development (Casimiro et al., 2003), and HD-Zip III genes participate in the development of lateral roots (Hawker and Bowman, 2004), we studied the root system in homozygous icu4-1 and heterozygous phb-1D plants at 14 days after germination. The length of the primary root of the icu4-1 mutant showed an average of $6 \mathrm{~cm}$, indicating a shortening as compared to the average of 8.4 $\mathrm{cm}$ observed in the En-2 accession $(\mathrm{P}<0.0001)$, as previously 
reported (Ochando etal., 2006), while the lengths of primary roots in the heterozygous phb-1D mutant and the Leraccession were not significantly different, with averages of 4.5 and 4.6 , respectively $(P>0.05)$. Both mutants showed a conspicuous reduction in the number of lateral roots, 1.9 lateral roots $/ \mathrm{cm}$ in icu4-1 and 1.5 lateral roots $/ \mathrm{cm}$ in $p h b-1 D$, as compared to 3.1 lateral roots $/ \mathrm{cm}$ in En-2 $(\mathrm{P}<0.0001)$ and 3.2 lateral roots $/ \mathrm{cm}$ in $\operatorname{Ler}(\mathrm{P}<0.0001)$. Therefore, the icu4-1 and $p h b-1 D$ alleles, in addition to their involvement in modifying vascular patterning, also alter the development of lateral roots.

\section{Discussion}

\section{The ICU4 gene contributes to pattern establishment in the eustele}

Our results provide evidence that the $C N A / / C U 4$ gene, which codes for the HD-Zip III transcription factor ATHB15 (Prigge et al., 2005), promotes vascular development through the stimulation of procambial cell proliferation. This is consistent with a previous work on ICU4I ATHB15and its Zinnia elegans ortholog ZeHB-13, indicating that both genes are expressed in procambial cells, and suggesting that they might function in the differentiation or maintenance of these cells (Ohashi-Ito and Fukuda, 2003). Thus, homozygous plants for the semidominant gain-of-function icu4-1 allele, which disrupts the negative control of /CU4by miR165/166, overexpress the gene (Ochando et al., 2006), and show more than twice the procambium, and a consequent increase of phloem and xylem, compared with the wild-type, supporting the notion that ICU4 promotes vascular development, as proposed for ATHB8, its closest paralog (Baima et al., 2001). Nevertheless, accurate quantification of a pattern element, like the amount of vasculature in shoots, should refer to the area of the developmental field in which such an element develops. Thus, the complexity of the leaf venation pattern has been quantified by the length and the number of vein branch points relative to the lamina area (Candela et al., 1999). We measured the total area of vascular bundles per inflorescence stem relative to the shoot area, finding that this value is approximately $25 \%$ greater in the homozygous icu4-1 mutant, which corroborates that this mutant produces more vascular tissue than the wild-type.

Most inflorescence stems of the En-2 accession show a eustele with eight vascular bundles, which are reduced to six or five in icu4-1 shoots, although with a penetrance that approaches $20 \%$. This phenotype represents a true reduction in the number of components of this shoot pattern element, since: 1) we have never observed fewer than seven vascular bundles in inflorescence stems of En-2, 2) the reduced number of bundles is always observed and even decreased in some double mutant combinations, like icu4-1 fil-3, and 3) a recent work has shown that mATHB15transgenic plants, which overexpress an ICU4 CDNA with silent mutations in the region complementary to miR165/166, also exhibit low number of vascular bundles and poor lignification of interfascicular fiber cells (Kim et al., 2005).

Auxin is involved in the establishment of vessel diameter and density along the plant axis (Aloni, 2004). Interestingly, the icu41 mutant overexpresses PINOID (PID) (Ochando et al., 2006), a gene that positively regulates the polar auxin flow. Thus, taking into account that vascular strands are induced along the preferred pathways of auxin flow, a higher rate of transport in the thick developing bundles of the icu4-1 mutant might deplete the auxin in the surrounding tissues that would be unable to differentiate new vascular elements, giving rise to the occasional reduction of bundle numbers. Alternatively, if there was a process of lateral inhibition by which vascular strands impeded the induction of additional bundles nearby through the action of an inhibitor, as suggested by the phenotype of the cov1 mutant (Parker et al., 2003), the thick vascular bundles of icu4-1 would produce high levels of the inhibitor, resulting in the reduced number of vascular bundles. Treatments of icu4-1plants with the synthetic auxin NAA produced an enhancement of the mutant phenotype. We think that this finding supports the inhibitor hypothesis, as plants treated with NAA would have an excess of auxin that would preclude its depletion in the proximity of developing bundles.

\section{The ICU4 gene contributes to the establishment of polarity in shoots}

Unlike other mutants carrying semidominant alleles of HD-Zip III genes, icu4-1 never shows the transformation of the normal collateral organization of tissues in vascular bundles to an amphivasal pattern. Nevertheless, double heterozygous plants carrying the icu4-1 and $p h b-1 D$ alleles exhibit a synergistic phenotype in their bundles, which show a remarkable amphivasal pattern, and some transgenic plants overexpressing the mutant icu4-1 cDNA (35S-/CU4-G189D transformants) display strongly adaxialized lateral organs (Ochando et al., 2006) and partially amphivasal vascular bundles (this work). These results indicate that the ICU4 product has both an adaxial activity and a function in the specification of the central-peripheral axis in shoot vascular bundles, as proposed for PHB and REV proteins (Emmery et al., 2003; Dinneny and Yanofsky, 2004; Zhong and Ye, 2004). That ICU4 and other HD-Zip III genes collaborate in the patterning of shoot vascular bundles is also suggested by the aberrant amphivasal bundles observed in inflorescence stems of triple mutants for null alleles of ICU4, PHB and PHV (Prigge et al., 2005).

Plants overexpressing a construct with silent mutations in the miRNA target ( $M A T H B 15$ transgenic plants) showed reduced numbers of collateral bundles (Kim et al., 2005). This phenotype is similar to that of 35S-/CU4-G189D transgenic plants exhibiting weak adaxial transformations in their leaves. Other class of 35SICU4-G189D plants showing stronger leaf aberrations, which suggests that they might be expressing the transgene at higher levels, presented a partial transformation to amphivasal polarity in their bundles. Thus, moderate expression of an miRNA-resistant form of $1 C U 4$ might cause reduced numbers of collateral bundles ( $m A$ THB15 plants, 35S-/CU4-G189D plants with weak adaxial transformations and some icu4-1 stems), while a higher expression would produce a change in the polarity of the bundles (35S-/CU4-G189D plants with stronger adaxial transformations). This suggests the participation of a mechanism of positional information for establishing the number of vascular bundles and their characteristic collateral pattern, which involves the transcriptional activity of ICU4 and other HD-Zip III genes, and their posttranscriptional regulation by miRNAs, which affects both the spatial expression of the genes and the abundance of transcripts. As suggested by the phenotypes of plants treated with NAA, this process would be influenced by auxin, which has been previously shown to interact with KANADI and HD-Zip III genes for pattern 
formation along the central-peripheral axis of the embryo (Izhaki and Bowman, 2007) and to induce the expression of several HDZip III genes, including ICU4 and PHB(Zhou et al., 2007).

\section{Synergistic and antagonistic interactions between mutant alleles of HD-Zip III genes}

A recent report has described the complexity of the interactions among HD-Zip III genes (Prigge et al., 2005). Our results make new contributions to this line of work. We have shown that icu41 partially suppresses the abaxial-to-adaxial transformations caused by $p h b-1 D$ in lateral organs, which suggests that the ICU 4 product, though itself showing adaxial activity (Ochando et al., 2006), antagonizes the function of the PHB transcription factor in establishing adaxial identity in lateral organs. However, we observed a synergistic interaction between both alleles in shoot vascular bundle patterning, which suggests that $/ C U 4$ and $P H B$ have overlapping functions in the bundles. Although there is a common mechanism at work to specify the adaxial-abaxial polarity in lateral organs and the pattern of shoot vascular bundles (Emery et al., 2003; Zhong and Ye, 2004), these results point out that there must be some differences between both processes. Moreover, we have seen that the icu4-1 allele is epistatic over loss-of-function alleles of $R E V$, playing the same role as the double combination of null alleles of CNA/ICU4 and ATHB8 in eliminating the Rev- phenotype (Prigge et al., 2005). Therefore, the overproduction of ICU4 caused by icu4-1 compensates for a loss of $R E V$ function, in agreement with the modest suppression of the Rev phenotype by the $P_{R E V}: C N A$ construct, which expresses the ICU4 wild type cDNA under the control of the REV promoter (Prigge et al., 2005).

These results pose the question of why loss-of-function and gain-of-function mutations in HD-Zip III genes produce similar phenotypes, such as the amphivasal vascular bundles seen in the double heterozygous icu4-1 phb-1D and the cna phb phv triple null mutant, or the rescue of the Rev- phenotype by cnalicu4 alleles with different genetic behaviors. Based on the ability proposed for HD-Zip III transcription factors to dimerize (Sessa et al., 1998; Ohashi-Ito et al., 2002), we suggest that the production of homo and heterodimers, with different activities depending on the protein(s) involved in the dimers, might account for the complex interactions shown by HD-Zip III genes. In this context, the phenotype of specific mutants should result from the types of dimers formed in the different tissues, which would depend ultimately on the relative level of each HD-Zip III product. This hypothesis would imply that HD-Zip III transcription factors are not fully equivalent in function, as has already been suggested (Prigge et al., 2005). However, although the formation of functionally different dimers might shed light on the behavior of HD-Zip III genes, given that the mechanism of action of these genes appears to be more resistant to loss-of-function mutations than to gain-of-function mutations, further studies will be needed to ascertain how HD-Zip III genes interact to establish developmental processes in specific organs.

\section{Materials and Methods}

\section{Plant materials and growth conditions}

Several Arabidopsis thaliana (L.) Heyhn. lines studied in this work were supplied by the Nottingham Arabidopsis Stock Centre (NASC). These included the Enkheim-2 (En-2) wild-type, the icu4-1 mutant (N400) in an En-2 genetic background (Serrano-Cartagena et al., 2000), the mutant phb-1D(N3761) (McConnell and Barton, 1998) in the Leraccession, and rev-1 (N3826) (Talbert et al., 1995), in the No-0 accession. The fil-3 mutant, in a Ler genetic background, was provided by G. Drews (Chen et al., 1999), and the rev-6 mutant in a Col background by S. E. Clark (Otsuga et al., 2001; Prigge et al., 2005). The kanamycin-resistant transgenic line 35S-/CU4-G189D overexpresses the mutant icu4-1cDNA (Ochando et al., 2006).

Seeds were first sterilized by washing for 8 minutes in $40 \%$ commercial bleach with $0.1 \%$ Triton X-100, followed by four washes with sterile water. The seeds were then spread in Petri dishes containing GM (Germination Medium: $0.5 X$ Murashige-Skoog with $1 \%$ sucrose) supplemented with 50 $\mu \mathrm{g} / \mathrm{ml}$ kanamycin when required. To assist uniform germination, seeds were kept at $4^{\circ} \mathrm{C}$ for 24 hours in the dark. Plants were grown in a Sanyo MLR-350H growth chamber under constant cool-white fluorescent light (7000 lux). All strains were grown at $21^{\circ} \mathrm{C}$, with the exception of those containing the phb-1Dallele that were gown at $18^{\circ} \mathrm{C}$. Three weeks after germination, plants were transferred to pots containing a 2:2:1 mixture of perlite, vermiculite and sphagnum moss, and watered twice a week with a mineral nutrient solution (Lincoln et al., 1990).

For auxin experiments, plants were grown on GM, and 15 days after sowing they were transferred to pots and watered with the mineral nutrient solution supplemented with $0.1,0.5$ or $1 \mu \mathrm{M}$ of naphthylacetic acid (NAA, Duchefa Biochemie). All the solutions were adjusted to contain the same volume of dimethyl sulfoxide (DMSO), used as a solvent for NAA. Results are presented for the highest concentration, $1 \mu \mathrm{M}$ NAA. Similar, though weaker, phenotypes were obtained when lower concentrations were used. Control plants were watered with the mineral nutrient solution supplemented with DMSO.

\section{Semiquantitative RT-PCR (SQRT-PCR)}

Plants were grown as indicated above and total RNA was isolated from leaves using the Nucleospin RNA plant kit (Macherey-Nagel) according to the manufacturer's instructions. Reverse transcription was performed as previously described (Ripoll et al., 2006). cDNA fragments were amplified using the following primers: $I A A 1,5^{\prime}$-ggattacccggagcacaag and 5'-ggagctccgtccatactcac (Yamazoe et al., 2005); IAA19, 5'tggtgacaactgcgaatacg-3' and 5'-tcactcgtctactcctctag-3' (Perri etal., 2005). After 25 PCR cycles, the amplification products (208 bp for IAA 1 and 150 bp for $I A A 19$ were run in $2 \%$ agarose gels and visualized by ethidium bromide staining. ACTIN2 (ACT2) expression was monitored as an internal control (An et al., 1996).

\section{Genetic interactions}

With the exception of $p h b-1 D P H B$ plants, homozygous parental lines were cross-fertilized. Double mutants were identified among the $F_{2}$ segregants by a differential phenotype, and confirmed by self-pollination of putative double mutants and production of $\mathrm{F}_{3}$ non-segregating progenies. In every $F_{2}$ segregation involving parental lines with different accession backgrounds we chose five double mutants and five single homozygous mutants for each allele involved for further analysis, in order to discard a possible effect of mixing backgrounds on the observed phenotypes. To obtain the icu4-1//CU4; phb-1DIPHB plants, the icu4-1 mutant was fertilized with pollen from the phb-1DPPB heterozygote. These double heterozygous plants were compared with mutant $F_{1}$ plants from a cross between phb-1D/PHB and En-2.

\section{Microscopy}

For plastic sections, tissue was vacuum infiltrated with $\mathrm{FAE}(45 \%$ ethanol, $5 \%$ glacial acetic acid, $1.85 \%$ formaldehyde, $1 \%$ Triton X-100) and fixed for 2 hours at room temperature. Samples were dehydrated through an ethanol series $(70 \%, 80 \%, 90 \%$ and $95 \%)$ and embedded in JB4 resin (Electron Microscopy Sciences). Sections 3-4 $\mu \mathrm{m}$ were cut with a Microm HM350S microtome, stained with $0.1 \%$ toluidine blue and observed using an ECLIPSE E800 microscope (Nikon) equipped with a 
COLORVIEW-III digital camera (Nikon). Images were analyzed with the analySIS software (Soft Imaging System $\mathrm{GmbH}$ ).

\section{Acknowledgements}

We thank C. Ferrándiz, S. Pelaz and H. Alonso-Cantabrana for their critical reading of the manuscript, and $M$. A. Climent and $A$. Baso for their technical assistance. We also thank J. L. Micol and M. R. Ponce for sharing unpublished results. We acknowledge the NottinghamArabidopsis Stock Centre (NASC) for supplying seeds, and S. E. Clark and G. Drews for kindly providing mutant lines. This work was supported by research grants BIO2002-04083-C03-03 from the Ministerio de Educación y Ciencia of Spain (MEC) to A.M.L. and BIO2006-04502 from MEC to A. V.; I.O. was supported by a graduate fellowship of the Generalitat Valenciana.

\section{References}

ALONI, R. (1987). Differentiation of vascular tissues. Annu. Rev. Plant Biol. 38: 179-204.

ALONI, R. (2004). The induction of vascular tissues by auxin. In: Davies P.J. editor, Plant Hormones: Biosynthesis, Signal transduction, Action! Kluwer Academic Publishers, Dordrecht (The Netherlands), p. 471-492.

ALTAMURA, M.M., POSSENTI, M., MATTEUCCI, A., BAIMA, S., RUBERTI, I. and MORELLI, G. (2001). Development of the vascular system in the inflorescence stem of Arabidopsis. New Phytol. 151: 381-389.

AN, Y.Q., MCDOWELL, J.M., HUANG, S., MCKINNEY, E.C., CHAMBLISS, S. and MEAGHER, R.B. (1996). Strong, constitutive expression of the Arabidopsis ACT2/ACT8 actin subclass in vegetative tissues. Plant J. 10: 107-121.

BAIMA, S., NOBILI, F., SESSA, G., LUCCHETTI, S., RUBERTI, I. and MORELLI, G. (1995). The expression of the Athb-8 homeobox gene is restricted to provascular cells in Arabidopsis thaliana. Development 121: 4171-4182.

BAIMA, S., POSSENTI, M., MATTEUCCI, A., WISMAN, E., ALTAMURA, M.M., RUBERTI, I. and MORELLI, G. (2001). The Arabidopsis ATHB-8 HD-Zip protein acts as a differentiation-promoting transcription factor of the vascular meristems. Plant Physiol. 126: 643-655.

BERLETH, T., MATTSSON, J. and HARDTKE, C.S. (2000). Vascular continuity and auxin signals. Trends Plant Sci. 5: 387-393.

CANDELA, H., MARTÍNEZ-LABORDA, A. and MICOL, J.L. (1999). Venation pattern formation in Arabidopsis thalianavegetative leaves. Dev. Biol. 205: 205216.

CAÑO-DELGADO, A., YIN, Y., YU, C., VAFEADOS, D., MORA-GARCÍA, S., CHENG, J.C., NAM, K.H., LI, J. and CHORY, J. (2004). BRL1 and BRL3 are novel brassinosteroid receptors that function in vascular differentiation in Arabidopsis. Development 131: 5341-5351.

CASIMIRO, I., BEECKMAN, T., GRAHAM, N., BHALERAO, R., ZHANG, H., CASERO, P., SANDBERG, G. and BENNETT, M.J. (2003). Dissecting Arabidopsis lateral root development. Trends Plant. Sci. 8: 165-171.

CHEN, Q., ATKINSON, A., OTSUGA, D., CHRISTENSEN, T., REYNOLDS, L. and DREWS, G.N. (1999). The Arabidopsis FILAMENTOUS FLOWER gene is required for flower formation. Development 126: 2715-2726.

DINNENY, J.R. and YANOFSKY, M.F. (2004). Vascular patterning: xylem or phloem? Curr. Biol. 14: R112-114.

EMERY, J.F., FLOYD, S.K., ALVAREZ, J., ESHED, Y., HAWKER, N.P., IZHAKI, A., BAUM, S.F. and BOWMAN, J.L. (2003). Radial patterning of Arabidopsisshoots by class III HD-ZIP and KANADI genes. Curr. Biol. 13: 1768-1774.

FUKUDA, H. (1997). Tracheary element differentiation. Plant Ce//9: 1147-1156.

HAWKER, N.P. and BOWMAN, J.L. (2004). Roles for Class III HD-Zip and KANADI genes in Arabidopsis root development. Plant Physiol. 135: 2261-2270.

IZHAKI, A. and BOWMAN, J.L. (2007). KANADI and Class III HD-Zip gene families regulate embryo patterning and modulate auxin flow during embryogenesis in Arabidopsis. Plant Cell 19: 495-508.

JACOBS, W.P. (1952). The role of auxin in differentiation of xylem around a wound. Am. J. Bot. 39: 301-309.

KIM, J., JUNG, J.-H., REYES, J.L., KIM, Y.-S., KIM, S.-Y., CHUNG, K.-S., KIM, J.A., LEE, M., LEE, Y., KIM, V.N., CHUA, N.-H. and PARK, C.-M. (2005). microRNA- directed cleavage of $A T H B 15$ mRNA regulates vascular development in Arabidopsis inflorescence stems. Plant J. 42: 84-94.

LINCOLN, C., BRITTON, J.H. and ESTELLE, M. (1990). Growth and development of the axr1 mutants of Arabidopsis. Plant Cel/2: 1071-1080.

MCCONNELL, J.R. and BARTON, M.K. (1998). Leaf polarity and meristem formation in Arabidopsis. Development 125: 2935-2942.

MCCONNELL, J.R., EMERY, J., ESHED, Y., BAO, N., BOWMAN, J. and BARTON, M.K. (2001). Role of PHABULOSA and PHAVOLUTA in determining radial patterning in shoots. Nature 411: 709-713.

MUDAY, G.K. and DELONG, A. (2001). Polar auxin transport: controlling where and how much. Trends Plant Sci. 6: 535-542.

MUDAY, G.K. and MURPHY, A.S. (2002). An emerging model of auxin transport regulation. Plant Cel/14: 293-299.

OCHANDO, I., JOVER-GIL, S., RIPOLL, J.J., CANDELA, H., VERA, A., PONCE, M.R., MARTÍNEZ-LABORDA, A. and MICOL, J.L. (2006). Mutations in the microRNA complementarity site of the INCURVATA4 gene perturb meristem function and adaxialize lateral organs in Arabidopsis. Plant Physiol. 141: 607619.

OHASHI-ITO, K., DEMURA, T. and FUKUDA, H. (2002). Promotion of transcript accumulation of novel Zinnia inmature xylem-specific HD-Zip III homeobox genes by brassinosteroids. Plant Cell Physiol. 43: 1146-1153.

OHASHI-ITO, K. and FUKUDA, H. (2003). HD-Zip III homeobox genes that include a novel member, $Z e H B-13$ (Zinnia)/ATHB-15 (Arabidopsis), are involved in procambium and xylem cell differentiation. Plant Cell Physiol. 44: 1350-1358.

OTSUGA, D., DEGUZMAN, B., PRIGGE, M.J., DREWS, G.N. and CLARK, S.E. (2001). REVOLUTA regulates meristem initiation at lateral positions. Plant J. 25: 223-236.

PARKER, G., SCHOFIELD, R., SUNDBERG, B. and TURNER, S. (2003). Isolation of $C O V 1$, a gene involved in the regulation of vascular patterning in the stem of Arabidopsis. Development 130: 2139-2148.

PERRY, J., DAI, X. and ZHAO, Y. (2005). A mutation in the anticodon of a single tRNA $^{\text {ala }}$ is sufficient to confer auxin resistance in Arabidopsis. Plant Physiol. 139: 1284-1290.

PRIGGE, M.J., OTSUGA, D., ALONSO, J.M., ECKER, J.R., DREWS, G.N. and CLARK, S.E. (2005). Class III homeodomain-leucine zipper gene family members have overlapping, antagonistic, and distinct roles in Arabidopsis. Plant Cell 17: $61-76$.

RIPOLL, J.J., FERRÁNDIZ, C., MARTÍNEZ-LABORDA, A. and VERA, A. (2006) $P E P P E R$, a novel K-homology domain gene, regulates vegetative and gynoecium development in Arabidopsis. Dev. Biol. 289: 346-359.

SACHS, T. (1981). The control of the patterned differentiation of vascular tissues Adv. Bot. Res. 9: 151-262.

SACHS, T. (1991). The canalisation of vascular differentiation. In Pattern formation in plant tissues, Cambridge University Press, Cambridge (UK), p. 70-87.

SAWA, S., WATANABE, K., GOTO, K., KANAYA, E., MORITA, E.H. and OKADA, K. (1999). FILAMENTOUS FLOWER, a meristem and organ identity gene of Arabidopsis, encodes a protein with a zinc finger and HMG-related domains. Genes Dev. 13: 1079-1088.

SERRANO-CARTAGENA, J., CANDELA, H., ROBLES, P., PONCE, M.R., PÉREZPÉREZ, J.M., PIQUERAS, P. and MICOL, J.L. (2000). Genetic analysis of incurvata mutants reveals three independent genetic operations at work in Arabidopsis leaf morphogenesis. Genetics 156: 1363-1377.

SESSA, G., STEINDLER, C., MORELLI, G. and RUBERTI, I. (1998). The Arabidopsis Athb-8, -9 and -14 genes are members of a small gene family coding for highly related HD-ZIP proteins. Plant Mol. Biol. 38: 609-622.

TALBERT, P.B., ADLER, H.T., PARKS, D.W. and COMAI, L. (1995). The REVOLUTA gene is necessary for apical meristem development and for limiting cell divisions in the leaves and stems of Arabidopsis thaliana. Development 121: 2723-2735.

YAMAMOTO, R., DEMURA, T. and FUKUDA, H. (1997). Brassinosteroids induce entry into the final stage of tracheary element differentiation in cultured Zinnia cells. Plant Cell Physiol. 38: 980-983.

YAMAZOE, A., HAYASHI, K.-I., KEPINSKI, S., LEYSER, O. and NOZAKI, H. (2005). Characterization of terfestatin A, a new specific inhibitor for auxin signaling. Plant Physiol. 139: 779-789.

YE, Z.H. (2002). Vascular differentiation and pattern formation in plants. Annu. Rev. 
Plant Biol. 53: 183-202.

YE, Z.H., FRESHOUR G., HAHN M.G., BURK D.H. and ZHONG R. (2002). Vascular development in Arabidopsis. Int. Rev. Cytol. 220: 225-56.

YOUNG, B.S. (1953). The effects of leaf primordia on differentiation in the stem. New Phytol. 53: 445-460.

ZHONG, R., TAYLOR, J.J. and YE, Z.H. (1997). Disruption of interfascicular fiber differentiation in an Arabidopsis mutant. Plant Cel/9: 2159-2170.

ZHONG, R. and YE, Z.H. (1999). IFL 1, a gene regulating interfascicular fiber differentiation in Arabidopsis, encodes a homeodomain-leucine zipper protein. Plant Cell 11: 2139-2152.

ZHONG, R. and YE, Z.H. (2004). amphivasal vascular bundle 1, a gain-of-function mutation of the IFL 1/REV gene, is associated with alterations in the polarity of leaves, stems and carpels. Plant Cell Physiol. 45: 369-385.

ZHOU, G.-K., KUBO, M., ZHONG, R., DEMURA, T. and YE, Z.-H. (2007). Overexpression of miR165 affects apical meristem formation, organ polarity establishment and vascular development in Arabidopsis. Plant Cell Physiol. 48: 391-404.

\section{Related, previously published Int. J. Dev. Biol. articles}

See our recent Special Issue Fertilization, in honor of David L. Garbers and edited by Paul M. Wassarman and Victor D. Vacquier at: http://www.ijdb.ehu.es/web/contents.php?vol=52\&issue=5-6

See our recent Special Issue Ear Development edited by Fernando Giraldez and Bernd Fritzsch at: http://www.ijdb.ehu.es/web/contents.php?vol=51\&issue=6-7

Plant microRNAs and development.

Sara Jover-Gil, Héctor Candela and María Rosa Ponce.

Int. J. Dev. Biol. (2005) 49: 733-744

Regulated RNA processing in the control of Arabidopsis flowering

Victor Quesada, Caroline Dean and Gordon G. Simpson

Int. J. Dev. Biol. (2005) 49: 773-780

Flower and fruit development in Arabidopsis thaliana

Pedro Robles and Soraya Pelaz

Int. J. Dev. Biol. (2005) 49: 633-643

Epidermal differentiation: trichomes in Arabidopsis as a model system

Swen Schellmann and Martin Hülskamp

Int. J. Dev. Biol. (2005) 49: 579-584

Vascular development: from precursor cells to branched arterial and venous networks

Anne Eichmann, Li Yuan, Delphine Moyon, Ferdinand leNoble, Luc Pardanaud and

Christiane Bréant

Int. J. Dev. Biol. (2005) 49: 259-267

Genetic and molecular analysis of INCURVATA2, a negative regulator of floral homeotic genes in the leaves of Arabidopsis thaliana MR Ponce, JM Barrero, $\mathrm{H}$ Candela, P Robles, JM Perez-Perez, P Piqueras, A Martinez-Laborda, JL Micol Int. J. Dev. Biol. (2001) 45: S53-S54

Interactions between INCURVATA genes in Arabidopsis thaliana

$S$ Jover-Gil, P Robles, H Candela, JL Micol

Int. J. Dev. Biol. (2001) 45: S45-S46

Interactions between venation pattern formation genes in Arabidopsis thaliana H Candela, A Martinez-Laborda, JL Micol Int. J. Dev. Biol. (2001) 45: S35-S36

2006 ISI **Impact Factor $=3.577^{* *}$

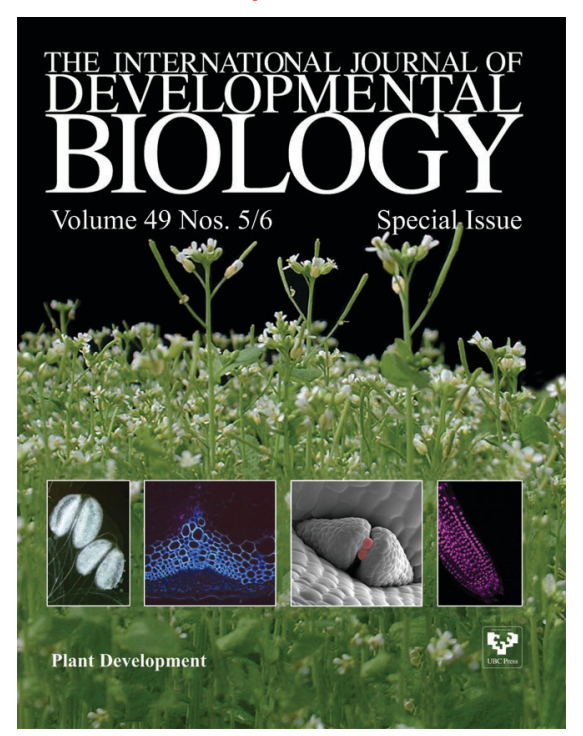

